\title{
OIAPOQUE, MUNICÍPIO DA MESORREGIÃO NORTE DO AMAPÁ: AVALIAÇÃO DAS POLÍTICAS E NÍVEIS DE INTEGRAÇÃO E TRANSFORMAÇÃO COM A GUIANA
} FRANCESA.

\author{
Lina Pereira Botelho ${ }^{1}$
}

José Alberto Tostes ${ }^{2}$

\begin{abstract}
RESUMO
O presente artigo relaciona as políticas públicas do Município de Oiapoque, pertencente à Mesorregião Norte do Estado do Amapá, com a Guiana Francesa. Os materiais utilizados como suporte para análise, da relação das políticas públicas entre Oiapoque e a Guiana Francesa, foram três artigos: "Avaliação da Sustentabilidade na Amazônia: a Mesorregião Norte do Amapá" (TOSTES, J. A.); "Ponte Brasil/ Guiana Francesa: Os Paradoxos da Integração num contexto Multi-escalar" (CASTRO, M. L.; PORTO, J.); "Transformações e Dinâmicas Urbanas ocorridas nas cidades do Estado do Amapá no período de 1950 a 2010" (TOSTES, J. A.). A análise dos artigos foi realizada no que se refere aos interesses na área de fronteira entre o Município de Oiapoque e a Guiana Francesa, além das medidas de Governança tanto do lado Brasileiro quanto do lado Francês.
\end{abstract}

PALAVRAS-CHAVE: Mesorregião Norte, Município de Oiapoque, Ponte Binacional, Fronteira, Desenvolvimento Sustentável, Desenvolvimento Endógeno.

\section{OIAPOQUE, MUNICIPALITY OF NORTH MESOREGION AMAPÁ : EVALUATION OF POLICIES AND INTEGRATION LEVELS AND PROCESSING WITH FRENCH GUYANA.}

\footnotetext{
${ }^{1}$ Arquiteta e Urbanista. Mestranda do Programa de Pós Graduação do Mestrado em Desenvolvimento Regional, pela Universidade Federal do Amapá - UNIFAP. linabotelho@ig.com.br.

${ }^{2}$ Possui graduação em Arquitetura e Urbanismo pela Universidade Federal do Pará (1988), mestrado em Historia e Teoria da Arquitetura pelo Instituto Superior de Artes (2000) e doutorado em Doutorado em Historia e Teoria da Arquitetura pelo Instituto Superior de Artes (2003). Atualmente é outro (especifique) do Instituto Superior de Artes e Professor Associado I da Universidade Federal do Amapá. Tem experiência na área de Arquitetura e Urbanismo, com ênfase em História da Arquitetura e Urbanismo, atuando principalmente nos seguintes temas: planejamento urbano regional, Desenvolvimento Regional, planejamento, Amapá e Urbanismo. Estágio de Pós doutorado concluído no Instituto de Estudos Urbanos Regionais da Universidade de Coimbra. Tostes.j@hotmail.com.
} 


\section{Revista Nacional de}

Gerenciamento de Cidades

ribeirinhas, indígenas e quilombolas), na luxuriante natureza e profusa biodiversidade e na abundância de recursos naturais, objeto de interesses internacionais (do capital), assume outras características específicas que têm a ver com o seu processo histórico, o processo de formação de suas cidades e sua fronteira internacional, que o liga à Europa, através da Guiana Francesa, departamento ultramarino francês.

O município de Oiapoque faz parte da Faixa de Fronteira e está interligado pela BR 156 (Corredor Transfronteiriço) à capital, Macapá, e à Guiana Francesa, através da ponte Binacional, que, embora terminada, não está, ainda, em funcionamento.

Variando entre um espectro que vai desde constituir "espaços de ninguém" e de periferia até assumir o caráter de espaços estratégicos, a compreensão dos territórios de fronteira nem sempre foi a mesma que se tem atualmente. De lugares isolados e distantes dos grandes centros, passaram a ser entendidos como espaços estratégicos, de segurança nacional, e, neste sentido, passaram a ser alvo de grandes investimentos por parte do governo central (Nascimento et al., 2010).

Estes investimentos, no caso do Estado do Amapá, atraíram cidadãos de outros estados, que vieram em busca de melhores condições de vida, e que devido a já ineficiente infraestrutura e falta de planejamento, provocaram inchaços populacionais e o surgimento de invasões e ocupações desordenadas. Esta situação ocorreu de forma agravante no Município de Oiapoque, que é portador de dificuldades, de forma mais severa, nos setores da saúde, habitação, educação, saneamento básico (coleta e tratamento de resíduos sólidos, abastecimento de água, fornecimento de energia), institucionais e de infraestrutura. Diante deste cenário o município necessita de ações planejadas que tardam acontecer.

A ponte constitui parte do processo de integração da América Latina, com vista a fortalecer o bloco e conferir-lhe peso político e econômico. A partir da ponte surgem questões em escala intermediária que diz respeito à integração da Amazônia, quanto sua articulação interna na tentativa da priorização das 


\section{Revista Nacional de}

Gerenciamento de Cidades

necessidades específicas da região para construção de um desenvolvimento endógeno. Na microescala, insinuam-se novas dinâmicas, passíveis de análise através da percepção de fenômenos que já começam ocorrer nas proximidades da fronteira.

O processo de utilização da Ponte Binacional que liga a Guiana Francesa ao Amapá vai além do término definitivo e conclusão de obra por parte do lado brasileiro. Ela depende da capacidade dos governos de ambas nacionalidades planejarem, formularem, programarem políticas e cumprirem funções para que haja interesse mutuo em desenvolver, à priori, as áreas de entorno a cabeceira da ponte e as margens das estradas. A eficiência na tomada de decisões será primordial para o desenvolvimento sustentável das regiões próximas e vinculadas a Ponte.

\section{AS QUESTÕES DA GOVERNANÇA NOS NÍVEIS DE INTEGRAÇÃO DO AMAPÁ COM A GUIANA FRANCESA.}

Num primeiro plano de análise, é útil refletir em que, no contexto histórico, o problema da governança no Amapá está instalado desde a fundação do Estado. Há mudanças no governo eleição após eleição, porém os problemas com a falta de transparência, responsabilidade, igualdade, efetividade, eficiência e prestação de contas são crônicos e causam transtornos de curto, médio e longo prazo à população.

O problema de governança ocorre, ainda, de forma mais severa no município de Oiapoque. A cidade passa por problemas, desde sua criação, no que diz respeito às instituições Municipal, Estadual e Federal. Oiapoque está localizado em uma área de fronteira, com boa parte do território de reserva e proteção ambiental e outra área de proteção indígenas, o que causa divergências nas decisões politicas tomadas nas diversas esferas governamentais. Não há integração entre as informações das instituições que permita uma boa administração dos 


\section{Revista Nacional de}

Gerenciamento de Cidades

recursos sociais, econômicos e ambientais existentes no Município que vise o desenvolvimento sustentável.

O diálogo deficiente entre as instituições do lado brasileiro estão, de alguma forma, atrasando a inauguração e a utilização definitiva da ponte Binacional. As instituições brasileiras e francesas ainda permanecem em fase de tomada de decisões para que não haja nenhum tipo de problema pós integração Brasil e França pela Ponte Binacional.

\section{AVALIAÇÃO DA SUSTENTABILIDADE NA AMAZÔNIA: A MESORREGIÃO NORTE DO AMAPÁ (TOSTES, J. A.)}

De acordo com Tostes, no Amapá, existem duas mesorregiões ${ }^{3}$, a norte e a sul. A mesorregião norte (Mapa 1) é composta por duas microrregiões: Amapá e Oiapoque. Na microrregião Amapá encontram-se Amapá, Pracuúba e Tartarugalzinho. Na microrregião Oiapoque, Calçoene e Oiapoque. As microrregiões referem-se às especificidades das mesorregiões ${ }^{4}$. No total de 5 municípios, a mesorregião norte do Amapá constitui-se de fragilidades, semelhanças de atividades urbanas, rurais e entraves políticos institucionais, que caracteriza um cenário bastante desfavorável ao desenvolvimento local destas cidades (Tostes, 2011).

\footnotetext{
${ }^{3}$ Entende-se por mesorregião uma área individualizada em uma Unidade da Federação que apresenta formas de organização do espaço geográfico definidas pelos processos sociais como determinante, o quadro natural como condicionante e a rede de comunicação e de lugares como elemento da articulação espacial. Esta delimitação possibilita ao espaço o alcance de uma identidade regional construída através, sobretudo, do seu processo histórico (IBGE, 1990).

${ }^{4}$ Segundo o IBGE (2014), o objetivo desta divisão regional é a de elaborar políticas públicas; subsidiar decisões quanto à localização de atividades econômicas, sociais e tributárias; subsidiar o planejamento, estudos e identificação das estruturas espaciais de regiões metropolitanas e outras formas de aglomerações urbanas e rurais.
} 


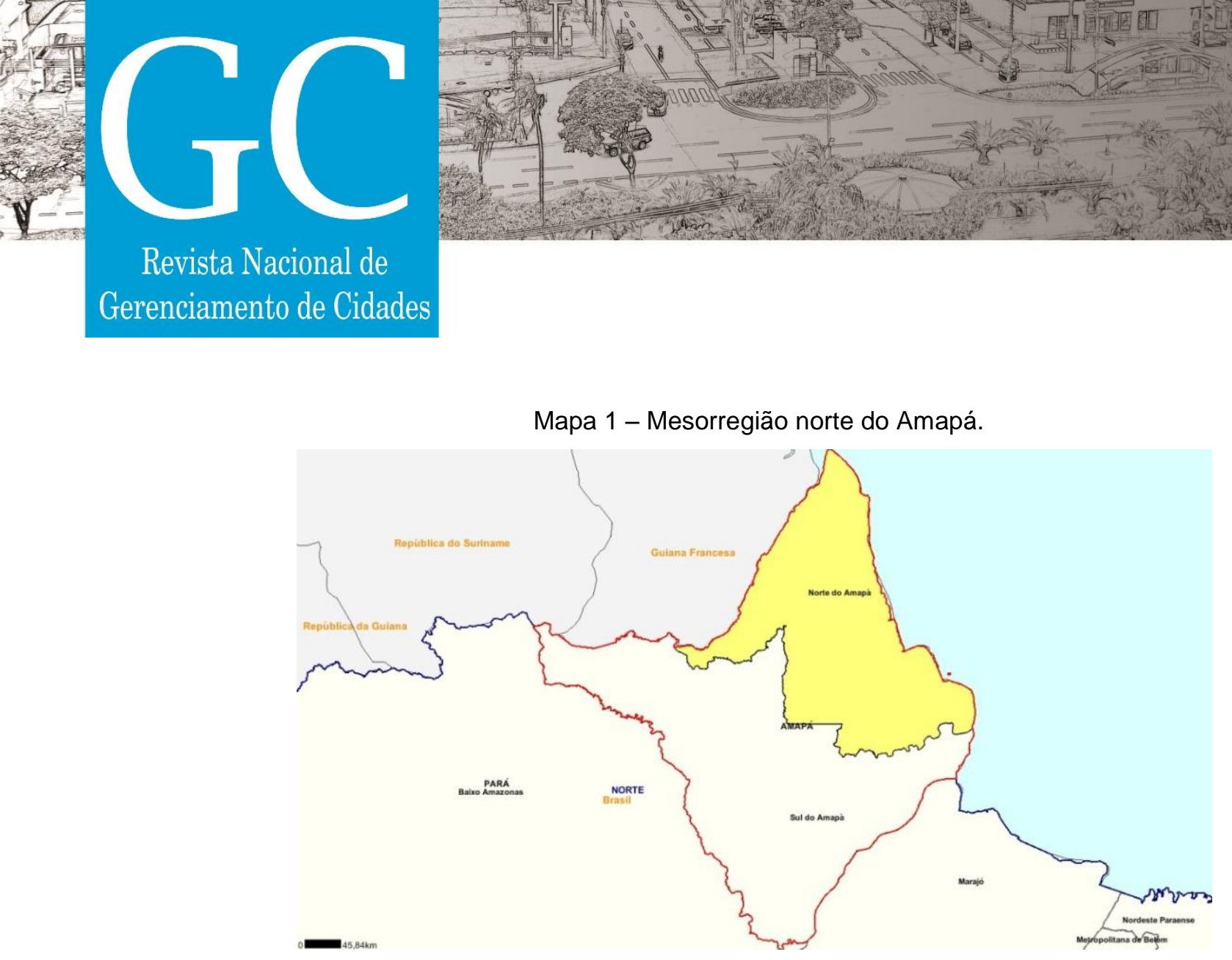

\section{Revista Nacional de}

Gerenciamento de Cidades

Fonte: Sistema IBGE de Recuperação Automática - SIDRA. Disponível em: $<$ http://www.sidra.ibge.gov.br>

Estes municípios da faixa de fronteira são municípios que possuem especificidades de formação territorial, demográfica, de ocupação, de função econômica, nem sempre conseguindo acompanhar a aceleração da nova configuração geopolítica decorrente do cenário da globalização.

Há uma dinâmica interessante que se tem percebido e que tem a ver com o fato de estes municípios (e o Estado) serem tratados como periféricos pelas elites locais regionais e pelos órgãos de planejamento federal, constituindo, em simultâneo, espaços considerados estratégicos por constituírem uma área de segurança nacional e geopoliticamente estratégica para a soberania nacional, como assinala Porto (2010, 2013; ver também Silva et al., 2013).

Referindo-se aos municípios da área de fronteira, entre as dificuldades que mais se destacam estão a grande debilidade institucional das administrações locais, sistema tributário eminentemente concentrador de recursos na União e nos estados, ausência de preparação e capacitação administrativa dos gestores públicos, inexistência de planejamento e de definição de gestão a longo e médio prazos. 


\section{Revista Nacional de}

Gerenciamento de Cidades

Para minimizar as dificuldades acima citadas, pode se pensar em um Desenvolvimento Sustentável para o Município de Oiapoque como forma de solução para determinados problemas que a cidade vem enfrentando, e que futuramente, com a finalização da pavimentação da BR 156 e a utilização da ponte binacional, podem vir a agravar ainda mais. Onde Ferreira (2012) define o desenvolvimento sustentável como o processo de transformações que, ocorrendo de forma harmoniosa em várias dimensões (espacial, ambiental, econômica, social, cultural e institucional), almeja a promoção humana integral, a cidadania plena e a equidade social, a paz e a segurança, um ambiente saudável e ecologicamente equilibrado, no contexto das gerações presentes e futuras e na direção de um mundo sustentável.

Assim sendo, o município de Oiapoque obteria uma grande melhoria politica, econômica e urbana, estaria precavido de determinadas situações como o inchaço populacional em decorrência da integração com a Guiana Francesa através da Ponte Binacional. Aspectos como a participação, a gestão financeira, gestão urbana, renda, meio ambiente (ar, água, resíduos), saúde, educação, habitação e cultura, contemplando um vasto rol de assuntos que podem ser relevantes para um planejamento que atenda a sustentabilidade.

No município de Oiapoque o esgoto não é tratado, o abastecimento de água é feito em condições precárias, sem tratamento e valorização dos resíduos e sem produção de alimentos em condições de proteção do meio ambiente (agricultura orgânica). A este respeito, não deixa de ser interessante o fato de o estado do Amapá ser um dos estados mais protegidos do País com $72 \%$ da sua área sob proteção, logo um enorme contrasenso.

É também relevante observar a dimensão político institucional, o baixo número de servidores com curso superior, e os problemas financeiros enfrentados pela prefeitura do municipio, indicando que a gestão urbana ainda tem muito que caminhar. Além da debilidade econômica de Oiapoque, que fragiliza os empresários do ramo turistico, hoteleiro e comerciantes. 


\section{Revista Nacional de}

\section{PONTE BRASIL/ GUIANA FRANCESA: OS PARADOXOS DA INTEGRAÇÃO NUM CONTEXTO MUITI-ESCALAR (CASTRO, M. L.; PORTO, J.)}

Segundo Porto e Castro, no nível de inteiração global, a Guiana é vista como um elo de integração para o Brasil, enquanto locus da interseção de diversos espaços geopolíticos: o espaço dos Departamentos Franceses da América, por exemplo. Desta forma a utilização da ponte poderá proporcionar ao Brasil uma nova ordem de contatos, através de vínculos políticos e culturais que a Guiana desfruta.

Entretanto do ponto de vista geofísico é o Amapá que deverá se tornar um importante elo de conexão para a Guiana. Portanto, a conexão com o Brasil representa não só a possibilidade de contato com a região Amazônica e com toda a economia mais desenvolvida do sul do continente, mas também uma abertura para o restante do mundo. Apesar de o Amapá não possuir ligação direta com outros estados brasileiros através de rodovias, a dinâmica fluvial local abre perspectiva de integração não só na esfera regional, mas mesmo em maior amplitude, oferecendo à Guiana novas opções de abastecimento interno ou escoamento de mercadorias por via marítima.

As mudanças geradas pela ponte Binacional, assim que permitirem o seu uso, irão dinamizar a região, criando novas articulações, mas também acarretando problemas de urbanização nas cidades de fronteira e problemas sociais em toda a área de influencia, especialmente no município de Oiapoque. Além da dinamização, há ainda, a possibilidade de intensificação dos fluxos de ilegais, pessoas que vão ilegalmente para a Guiana Francesa a procura de melhoria de vida, o que preocupa as autoridades.

Para Porto e Castro, do ponto de vista regional, a melhoria de transporte poderá servir ao desenvolvimento endógeno, mas ao mesmo tempo ela vai estar inserida nas dinâmicas globais e se prestará ao eventual escoamento dos produtos de exploração da grande base natural da região, com impactos negativos. Ainda segundo os autores Porto e Castro, assim, torna-se imperativo desenvolver políticas 


\section{Revista Nacional de}

Gerenciamento de Cidades

públicas preventivas na região para mitigar estes problemas, avaliando-se os impactos nas diversas escalas criando estratégias que conduzam ao desenvolvimento sustentável.

O relativo isolamento em que se encontra o Estado do Amapá prejudica a sua integração aos mercados nacionais e internacionais, mas ao mesmo tempo fortalece determinadas dinâmicas nacionais e internacionais, regionais e locais, protegendo-as da competição desigual a que estariam sujeitas se conectadas às eficientes redes que atuam nas macro escalas.

O desenvolvimento sustentável está desta forma intrinsicamente ligado ao território e tem grande interseção com o conceito de desenvolvimento endógeno e regional, que é a base de um novo paradigma surgido a partir do inicio dos anos 80 , que enxerga o território enquanto "agente de transformação e não mero suporte dos recursos e atividades econômicas, uma vez que há interação entre as empresas e os demais atores que se organizam para desenvolver a economia e a sociedade" (BARQUERO, 2002. p. 39).

A finalização da pavimentação da BR 156 e o inicio da utilização da Ponte Binacional possuem um potencial contraditório e poderão servir tanto ao desenvolvimento endógeno e sustentável quanto ao crescimento indiscriminado e predatório.

\section{TRANSFORMAÇÕES E DINÂMICAS URBANAS OCORRIDAS NAS CIDADES DO AMAPÁ NO PERÍODO DE 1950 A 2010 (TOSTES, J. A.)}

As cidades amapaenses, assim como as demais cidades da Amazônia também estão influenciadas pelos projetos capitalistas e grandes empreendimentos privados. Muitos destes projetos e discursos desenvolvimentistas foram induzidos por práticas intervencionistas do Governo Federal, sob a alegação da inelutável necessidade de ocupação de áreas vazias demograficamente (PORTO, 2003). Com o município de Oiapoque não ocorreu de forma diferente. Sua localização 


\section{Revista Nacional de}

Gerenciamento de Cidades

estratégica no extremo norte do Estado evidenciou seu potencial fronteiriço para a integração do Brasil e do Amapá com a Guiana Francesa.

Porém, antes que o Governo Federal se desse conta deste potencial o capital privado passou a explorar os recursos naturais da região, e o uso diversificado de matéria prima. Sem valor agregado decorrentes de processos de transformação, em geral produzidos fora do País, apresentou resultados tímidos para um contexto que abriga inúmeras riquezas naturais. $O$ governo não revela 0 viés político-econômico que permeou as suas ações, mas interfere progressivamente no modo dos habitantes da região, sobretudo nas questões de natureza cultural. (OLIVEIRA, 2004).

Diante de tais práticas, o inchaço populacional foi inevitável, com implicações na constituição de novos aglomerados urbanos decorrentes de ocupação desordenada e sem o mínimo de planejamento urbano espacial. Ressaltase que parte dessa massa populacional não consegue colocação profissional, instituindo-se assim, um exército de mão-de-obra pouco qualificada e ociosa que busca sobrevivência e fixação nas condições mais adversas possíveis.

As atividades que influenciam o núcleo urbano do Município de Oiapoque estão configuradas entre as atividades clandestinas, garimpos ilegais, invasões e outras atividades, como o turismo sexual. Verifica-se que entre as atividades clandestinas as irregularidades de obras, camelôs, ambulantes, ocupação de áreas de rios, várzeas ou igarapés. $\mathrm{Na}$ atividade de garimpos ilegais, destaca-se o Oiapoque, a presença desta atividade está registrada em tudo na cidade, no comércio, serviços, equipamentos, nas instituições, sendo hoje um dos maiores entraves. Além das invasões que vem ocorrendo, seja por problema de falta de moradia ou pelos índices migratórios que estão aumentando cada vez mais.

As condições de infraestrutura urbana de Oiapoque, tem como a principal adversidade para exercer o controle da fiscalização urbana, fato consequente dos principais problemas de planejamento e gestão urbana, o planejamento urbano é determinante para as condições da infraestrutura que refletem automaticamente 


\section{Revista Nacional de}

Gerenciamento de Cidades

como a principal adversidade para a fiscalização urbana. As invasões são de extrema adversidade ao controle da fiscalização urbana, na medida em que elas causam a expansão desorganizada do traçado urbano, surgem áreas da cidade sem infraestrutura e se caracterizam como sendo uma expansão totalmente irregular.

O município de Oiapoque, assim como os demais municípios amapaenses, revelam a face cruel dos municípios amazônicos. A falta de cumplicidade entre as esferas administrativas e de poder tem contribuído para a queda da qualidade de vida seja pela não oferta de serviços urbanos seja pela não melhoria dos serviços de transporte coletivo, água, esgoto, pavimentação, sistema de trânsito, entre outros.

\section{CONSIDERAÇÕES FINAIS}

Os Projetos estruturais e estruturantes não tem sido suficientes para amenizar ou reduzir as adversidades de Oiapoque, apesar de alguns investimentos pontuais, o próprio entorno da ponte binacional é um claro exemplo de um cenário nebuloso para o desenvolvimento futuro. Pois, a ponte deverá ter fortes impactos ambientais, sociais e econômicos, com efeitos marcantes sobre as populações locais e sobre o processo de urbanização. A cidade de Oiapoque de certo será a mais afetada, mas toda a população das comunidades vizinhas irão sofrer pressões, por meio de uma série de mudanças de caráter político, administrativo e geográfico, sob ordem física, material ou simbólica.

Além dos problemas de ordem urbana, as vias de transportes melhoradas vão abrir oportunidades para a exploração não sustentável da base natural local. A integração ainda vai romper um relativo grau de imunidade que o departamento francês detém com relação à amplitude dos problemas das regiões vizinhas, aumentando a permeabilidade das fronteiras e a vulnerabilidade a tráficos diversos. De acordo com o modo que a fronteira brasileira vem sendo tratada com descaso por parte das instituições governamentais, a fronteira do município de Oiapoque 


\section{Revista Nacional de}

Gerenciamento de Cidades

sofrerá com a exploração descabida, indevida e ilegal, tornando-se mais frágil do que já é atualmente.

Contudo, apesar dos pontos negativos, o município de Oiapoque, que faz parte da Mesorregião Norte do Estado, e assim sendo desencadeará os benefícios por ele obtidos através da conclusão da pavimentação da BR 156 e da utilização da Ponte Binacional, levará ao fortalecimento regional em busca de um desenvolvimento endógeno, ao mesmo passo que poderá estimular o desenvolvimento de outros setores, aproveitando a abertura de mercados externos para o Brasil, e o próprio mercado brasileiro que tem o potencial para determinados produtos.

Não há diagnóstico definitivo sobre a abertura da Ponte Binacional, assim como ela pode promover a integração regional, também poderá gerar conflitos e acentuar diferenças políticas e ideológicas; poderá fornecer elementos para busca da sustentabilidade, mas também servir a propósitos de exploração e de destruição do meio ambiente; o comércio entre os dois lados da fronteira poderá ser estimulado, mas tráficos também poderão intensificar.

Assim, mais importante do que se preocupar com as consequências da abertura da ponte, é a construção de diretrizes políticas e administrativas comuns entre os países beneficiados com o seu uso, que possibilitam o desenvolvimento econômico e social na região, fazendo ainda face ao desafio ecológico que a questão ambiental impõe.

A integração entre o Brasil e a França, através da abertura da Ponte Binacional entre Amapá e Guiana Francesa, inevitavelmente ocasionará transformações na dinâmica urbana, não só no Município de Oiapoque, mas na região de entorno e as margens da BR 156. Não há alternativa senão trabalhar em conjunto e usar o poder coletivo para criar uma relação transfronteiriça melhor. A totalidade das transformações levará à problemas comuns entre os países, que deverão ser administrados das diversas maneiras pelas suas respectivas instituições 
Revista Nacional de

Gerenciamento de Cidades

com o objetivo de resolvê-los. Será um processo contínuo pelo qual será possível acomodar interesses conflitantes ou diferentes e realizar ações cooperativas.

\section{REFERÊNCIAS BIBLIOGRÁFICAS}

BARQUERO, A.V. Desenvolvimento Endógeno em tempos de Globalização. Porto Alegre: UFRGS Editora. 2002.

CASTRO, M. L.; PORTO, J. Ponte Brasil/ Guiana Francesa: Os Paradoxos da Integração num contexto Multi-escalar.

Ferreira, J. F. C., 2012. A Sustentabilidade do Alto Douro Vinhateiro: realidade ou utopia? Contributo para a avaliação e melhoria da sustentabilidade da região. Tese de Doutorado. Lisboa: Faculdade de Ciências Sociais e Humanas (UNL).

Instituto Brasileiro de Geografia e Estatística, 2015. Divisão Regional. Disponível em: <http://www.ibge.gov.br/home/geociencias/geografia/default_div_int.shtm>. [Consult. a 26 de junho de 2015].

Nascimento, D. M. et al. 2010. Estado, fronteira e redes na Amazônia: uma contribuição ao debate. In: Porto, J. L. P. et al., 2012. Interações Fronteiriças no Platô das Guianas: Novas construções, novas territorialidades. Rio de Janeiro: Publit, vol. 1, p. 17-44.

OLIVEIRA. J.A. A cultura nas (das) pequenas cidades sustentáveis da Amazônia Brasileira. In: VIII Congresso Brasileiro Luso-Afro-Brasileiro de Ciências Sociais, 2004. Coimbra. Anais eletrônicos... Centro de Estudos Sociais, Faculdade de Economia, Universidade de Coimbra: 2004.

PORTO, J.L.R. Amapá: Principais Transformações Econômicas e Institucionais (1943-2000). Macapá: SETEC. 2003.

Porto, J. L. R., 2010. A Condição Periférico-Estratégica da Amazônia Setentrional: A inserção do Amapá no Platô das Guianas. In: Porto, J. L. R. et al., 2010. Interações Fronteiriças no Platô das Guianas. 1 ed., Rio de Janeiro: Publit, v. 1, p. 139-160.

Porto, J. L. R., 2013. Expectativas da fronteira da Amazônia Setentrional: a busca pela interação do Platô das Guianas. In: Porto, J. L. R. et al., 2013. Dinâmicas periférico-estratégicas da fronteira da Amazônia Setentrional: das políticas públicas e redes institucionais à integração espacial. Rio de Janeiro: Publit, p. 165-183.

Silva, A. R. F. et al., 2013. Pensando a diferenciação socioespacial na Amazônia: a sub-região fronteiriça internacional dos estados do Pará e Amapá. In: Porto, J. L. R. et al, 2013. Dinâmicas periférico-estratégicas da fronteira da Amazônia Setentrional: das políticas públicas e redes institucionais à integração espacial. Rio de Janeiro: Publit, p. 31-65.

TOSTES, J. A., 2011. Transformações urbanas das pequenas cidades amazônicas (AP) na faixa de fronteira setentrional. Rio de Janeiro: Publit.

TOSTES, J. A. Avaliação da Sustentabilidade na Amazônia: a Mesorregião Norte do Amapá.

TOSTES, J. A. Transformações e Dinâmicas Urbanas ocorridas nas cidades do Estado do Amapá no período de 1950 a 2010. 